\title{
Rhizobium-Induced Calcium Spiking in Lotus japonicus
}

\author{
Jeanne M. Harris, ${ }^{1}$ Rebecca Wais, ${ }^{2}$ and Sharon R. Long ${ }^{2}$ \\ ${ }^{1}$ Department of Botany and Agricultural Biochemistry, University of Vermont, Burlington, VT 05405-0086, U.S.A.; ${ }^{2}$ Howard \\ Hughes Medical Institute, Department of Biological Sciences, Stanford University, Stanford, CA 94305-5020, U.S.A.
}

Submitted 12 August 2002. Accepted 15 December 2002.

\begin{abstract}
Legumes and rhizobium bacteria form a symbiosis that results in the development of nitrogen-fixing nodules on the root of the host plant. The earliest plant developmental changes are triggered by bacterially produced nodulation (Nod) factors. Within minutes of exposure to Nod factors, sharp oscillations in cytoplasmic calcium levels (calcium spiking) occur in epidermal cells of several closely related legumes. We found that Lotus japonicus, a legume that follows an alternate developmental pathway, responds to both its bacterial partner and to the purified bacterial signal with calcium spiking. Thus, calcium spiking is not restricted to a particular pathway of nodule development and may be a general component of the response of host legumes to their bacterial partner. Using Nod factor-induced calcium spiking as a tool to identify mutants blocked early in the response to Nod factor, we show that the $L$. japonicus Ljsym22-1 mutant but not the Ljsym30 mutant fails to respond to Nod factor with calcium spiking.
\end{abstract}

The symbiosis between legumes and rhizobium results in the development of nitrogen-fixing nodules on the root of the host plant. The formation of these nodules requires the active participation of both plant and bacterial partner as they signal back and forth to coordinate each other's development. The rhizobial nodulation signal, or Nod factor, triggers a cascade of events in the host plant, leading to formation of a nodule primordium by root cortical cells and, ultimately, to bacterial invasion of that primordium through root hair cells. Purified Nod factor can produce many of these changes on its own, including root hair deformation, changes in gene expression and, in some legumes, cortical cell dedifferentiation and proliferation (Hayashi et al. 2000; Heidstra and Bisseling 1996; Niwa et al. 2001).

The process of nodule development from the initial encounter of plant and bacteria to the final step of nitrogen fixation takes more than a week, but physiological responses within the plant can be detected much sooner. Within the first five minutes, a series of ion fluxes in root hair cells, beginning with a rapid calcium influx and subsequent potassium efflux, lead to plasma membrane depolarization and, shortly thereafter, intracellular alkalinization. At approximately ten minutes, periodic oscillations in intracellular calcium levels, known as calcium spiking, initiate in epidermal cells and continue over the course of the next hour. These events are all rapid responses that occur well before the morphological events such as root hair curling (6 h) and cell divisions (24 h) (Cárdenas et al. 2000).

With the exception of the rapid rise in intracellular calcium levels (Cárdenas et al. 1999; Ehrhardt et al. 1996; Felle et al.

Corresponding author: J. M. Harris; E-mail: jmharris@zoo.uvm.edu; Fax: (802) 656-0440.
1998; Gehring et al. 1997), most of these early physiological responses have been examined only in a single legume species (Cárdenas et al. 2000). Calcium spiking, however, has been examined in several legume species (Ehrhardt et al. 1996; Wais et al. 2000; Walker et al. 2000) and is the only early host physiological response to Nod factor that has also been shown to be induced by live bacteria (Wais et al. 2002) or to correlate genetically with nodulation (Ehrhardt et al. 1996; Wais et al. 2000; Walker et al. 2000).

Calcium spiking is a widespread phenomenon observed across kingdoms (Berridge et al. 1998). In plants, calcium spiking has been detected in a unicellular green alga (Bauer et al. 1997) but only in two cell types in higher plants: legume root hairs in response to Nod factor (Ehrhardt et al. 1996; Wais et al. 2000; Walker et al. 2000) and guard cells in response to abscisic acid signaling (McAinsh et al. 1995; Staxén et al. 1999). Calcium spiking plays a functional role in lymphocyte activation, when it regulates cell fate and gene expression (Dolmetsch et al. 1998; Li et al. 1998). In plants, calcium spiking in guard cells has recently been shown to regulate stomatal opening (Allen et al. 2001).

Although Nod factor-induced calcium spiking has been observed in several legumes, all are closely related species (R. Wais and S. Long, unpublished data; D. Ehrhardt, A. Downie, and S. Long, unpublished data; Ehrhardt et al. 1996; Wais et al. 2000; Walker et al. 2000). The legume family is one of the largest plant families, comprising more than 18,000 species, most of which have the ability to nodulate. Within this family, several different kinds of nodules have evolved, reflecting different patterns of development. The most prevalent pattern of nodule development is indeterminate, characterized by the development of a persistent apical meristem. The other major nodule type is determinate, in which the organ lacks an apical meristem and, once the primordium is formed, grows largely by cell expansion (Hirsch 1992). All legume species characterized for calcium spiking to date follow the same pattern of nodule development, i.e., indeterminate. Although spatial and temporal fluctuations have been reported in the determinate nodulator, Phaseolus vulgaris, the hallmarks of calcium spiking were not demonstrated, i.e., the characteristic shape of the spike (a very sudden increase in calcium followed by a more gradual decline) and a regular period (Meyer and Stryer 1988; Thomas et al. 1996).

Since rhizobium-induced calcium spiking had only been characterized in legumes that follow an indeterminate pattern of nodule development, we wondered whether this potential signaling step was restricted to indeterminate nodule development or whether it was a more general response of legumes to their rhizobial partner. To distinguish between these two possibilities, we examined calcium levels in root hairs of the model legume Lotus japonicus, which forms determinate nodules (Handberg and Stougaard 1992). We found that L. japonicus 
responds to both rhizobium bacteria and Nod factor with calcium spiking, indicating that rhizobium-induced calcium spiking is not limited to legumes that follow an indeterminate pattern of nodule development and may be a general component of the response of host legumes to their bacterial partner.

Since Nod factor-induced calcium spiking is the earliest reported response of $L$. japonicus to its bacterial partner, it has value as an assay to distinguish mutants with very early blocks to nodulation (Ehrhardt et al. 1996; Wais et al. 2000; Walker et al. 2000). Several L. japonicus mutants have been identified that have defects early in the development of the rhizobiumlegume symbiosis (Bonfante et al. 2000; Schauser et al. 1998; Szczyglowski et al. 1998). We found that Ljsym22-1 mutants but not Ljsym30 mutants fail to show calcium spiking in response to purified Nod factor. Thus, the LjSym 22 gene is a candidate for a gene required for Nod factor perception and signal transduction or for the mechanism of calcium spiking itself.

\section{RESULTS}

\section{L. japonicus root hairs respond to induced $M$. loti bacteria} with cytoplasmic calcium oscillations.

To ask whether a legume that follows a determinate pattern of nodule development is capable of rhizobium-induced calcium spiking, we observed calcium levels in L. japonicus roots hairs before and after addition of its bacterial partner,
Mesorhizobium loti. In order to visualize cytoplasmic calcium levels in living cells, we injected dextran-linked, calciumsensitive Oregon Green dye into individual root hairs and monitored changes in fluorescence intensity in the presence and absence of $M$. loti bacteria (discussed below).

Bacterial genes required for nodulation (nod genes) are only transcribed in the presence of chemical signals (inducers) produced by the plant host. Since induction of nod gene expression and subsequent production of Nod factor takes a variable amount of time, we wanted to eliminate that variable in such a closely timed experiment and to use bacteria in which nod gene expression had already been induced. At the start of this project, the plant inducer of the $M$. loti nod genes was unknown, so we used an inducible system transferring the nodD gene from Rhizobium leguminosarum bv. trifolii, which responds to naringenin, into M. loti (Lopez-Lara et al. 1995), generating the JH11 strain (discussed in detail below).

We found that $M$. loti in which nod gene expression has been induced elicit a calcium spiking response in L. japonicus root hairs (Fig. 1, Table 1). Interestingly, some rhizobium species are able to trigger calcium spiking even in the absence of a plant inducer (Wais et al. 2002). To ask whether induction of nod gene expression in $M$. loti was required to elicit a calcium spiking response, we added $\mathrm{JH} 11$ bacteria grown in the absence of naringenin (i.e., nod genes uninduced) to L. japonicus roots. We found that $\mathrm{JH} 11$ bacteria in which the nod genes had

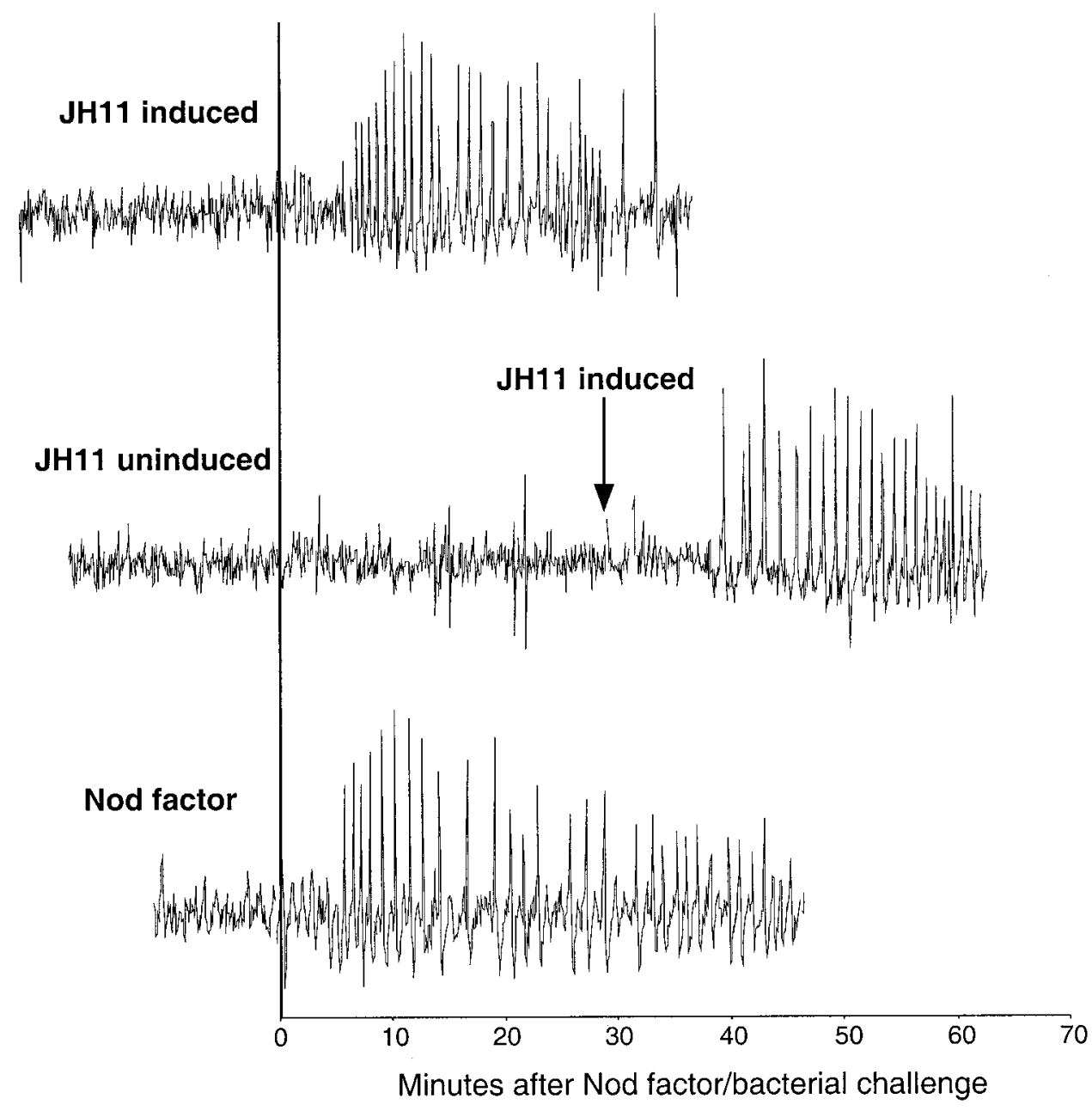

Fig. 1. Calcium spiking in Lotus japonicus root hairs in response to Mesorhizobium loti bacteria and purified M. loti Nod factor. Each trace represents calcium levels in an individual root hair cell. Purified Nod factor or $M$. loti bacteria (strain JH11) were added at time 0 . In the second trace, after more than 30 min without a calcium spiking response to the uninduced bacteria, induced JH11 bacteria were added as a positive control (arrow). Relative calcium levels were monitored using Oregon green fluorescence. Data was graphed as the difference in fluorescence intensity between sequential timepoints. 
not been induced failed to trigger calcium spiking in 10 of 10 L. japonicus root hairs. To demonstrate that these cells were capable of carrying out rhizobium-induced calcium spiking, we challenged them with induced JH11 bacteria. We found that five of these cells initiated spiking within $20 \mathrm{~min}$ of the addition of naringenin-induced JH11 bacteria (Fig. 1). This number is similar to that observed in L. japonicus plants stimulated only with induced JH11 bacteria (Table 1). Thus induction of the $M$. loti nod genes appears to be required for the initiation of calcium spiking in L. japonicus root hairs.

\section{M. loti-induced calcium spiking in host plants is mediated by Nod factor.}

Since the initiation of calcium spiking in L. japonicus is dependent upon induction of the $M$. loti nod genes, we wondered whether calcium spiking could be triggered by the ultimate product of the nod gene-encoded enzymes, Nod factor. We found that purified M. loti Nod factor (gift of C. Pacios Bras and H. Spaink, Leiden University, The Netherlands) induces calcium spiking in growing L. japonicus root hairs that appeared similar to the calcium spiking response seen with preinduced bacteria (Fig. 1). This finding indicates that Nod factor is sufficient to cause calcium spiking in L. japonicus, just as it is in legumes that form indeterminate nodules (Ehrhardt et al. 1996).

Calcium spiking is a specific type of signaling event characterized by regular oscillations that form "spikes". The spike refers to the shape of the calcium elevation, a very sudden increase in calcium followed by a more gradual decline. This characteristic shape of the spike reveals the operation of the underlying mechanisms of rapid release and more gradual pumping back into stores, as described in animal systems (Meyer and Stryer 1988; Thomas et al. 1996). The second feature that characterizes calcium spiking is its repetitive nature; calcium spiking has a regular period. The calcium spiking we observed in the L. japonicus root hair cells exhibits these two hallmarks of calcium spiking (Fig. 1).

In order to determine whether the calcium spiking observed in L. japonicus root hairs was comparable to that observed in other legume species, we measured two parameters of spiking: i) lag, the time between addition of bacteria or Nod factor and initiation of calcium spiking, and ii) period, the average time between spikes (discussed below). We found that with respect to these two parameters, calcium spiking behavior in L. japonicus is comparable to that observed in other legume species whether triggered by live bacteria or purified Nod factor (Table 1). Thus, a legume that forms determinate nodules responds to its rhizobial partner with Nod factor-induced calcium spiking, just as legumes that form indeterminate nodules do.

\section{Analysis of calcium spiking}

in $L$. japonicus nodulation mutants.

Recently, several L. japonicus mutants that are blocked in the very early steps of nodulation have been described (ImaizumiAnraku et al. 1997; Schauser et al. 1998; Szczyglowski et al. 1998). Nod factor-induced calcium spiking is a much earlier event than any that has been assayed in these mutants. To determine whether any L. japonicus mutants were blocked before or after calcium spiking, we examined whether two mutants, Ljsym 22-1 and Ljsym30, blocked early in the nodulation pathway (Szczyglowski et al. 1998), were able to respond to purified Nod factor with regular calcium spiking. Ljsym22-1 does not exhibit any of the early nodulation responses assayed and thus is blocked at an early point in the symbiosis (Table 2). We found that Ljsym22-1 mutants also fail to exhibit calcium spiking in response to M. loti Nod factor (Fig. 2). In contrast, Ljsym30, which is blocked at a later step after the initiation of nodule primordia (Table 2), is able to respond to both its bacterial partner $M$. loti and to purified Nod factor with calcium spiking (Fig. 2, Table 1). Thus the wild-type function of the Ljsym 22 gene is required either for perception or early transduction of the Nod factor signal upstream of calcium spiking or for calcium spiking itself. The Ljsym30 gene, however, appears to be required downstream, or independently, of calcium spiking.

\section{DISCUSSION}

During the establishment of their symbiosis, legumes and their rhizobial partners signal back and forth to coordinate the development of a mature, nitrogen-fixing nodule. Perception of the potent bacterial signaling molecule, Nod factor, triggers a series of changes in the host root, ultimately leading to the formation of a nodule primordium. One of the earliest responses of alfalfa to Nod factor is the initiation of periodic oscillations in calcium levels within the cytoplasm of root hair cells within a few minutes of exposure. Whereas several indeterminate legumes have been tested for calcium spiking behavior (Ehrhardt et al. 1996; Wais et al. 2000; Walker et al. 2000), our study is the first report of rhizobium-induced calcium spiking in a legume that forms determinate nodules.

In this paper, we show that the legume L. japonicus, which forms determinate nodules, also responds to its rhizobial partner $M$. loti by initiating calcium spiking in root hair cells. The ability of $M$. loti to induce calcium spiking is correlated with the production of Nod factors; induction of the bacterial nod genes is required for calcium spiking, and purified Nod factor, the end-product of the nod gene-encoded biosynthetic pathway,

Table 1. Calcium spiking responses of individual root hair cells in wild-type and mutant plants ${ }^{\mathrm{a}}$

\begin{tabular}{|c|c|c|c|c|c|c|}
\hline Plant genotype & JH11 & NF & \# Cells spiking/\# cells injected (\# plants) & $\%$ Cells spiking & Lag in min & Period in $\mathrm{s}$ \\
\hline \multirow[t]{2}{*}{ Wild type (Gifu) } & + & & $22 / 33(8)$ & $67^{b}$ & $11.1( \pm 4.2)$ & $76( \pm 3)$ \\
\hline & & + & $18 / 26(7)$ & $69^{b}$ & $7.2( \pm 0.9)$ & $98( \pm 9)$ \\
\hline \multirow[t]{2}{*}{ Ljsym30 } & + & & $5 / 14(3)$ & $36^{\mathrm{b}}$ & $9.4( \pm 1.9)$ & $72( \pm 5)$ \\
\hline & & + & $6 / 12(3)$ & $50^{\mathrm{b}}$ & N.D. & N.D. \\
\hline Ljsym22-1 & & + & $0 / 25(5)$ & 0 & & \\
\hline Alfalfa ${ }^{c}$ & & + & $36 / 40$ & 90 & $9.4( \pm 1.1)$ & $60( \pm 4)$ \\
\hline M. truncatula ${ }^{\mathrm{d}}$ & & + & $38 / 46(14)$ & $83^{b}$ & 11.1 & 102 \\
\hline $\mathrm{Pea}^{\mathrm{e}}$ & & + & $10 / 10(10)$ & $100^{\mathrm{b}}$ & Range: 5 to 15 & $\sim 60$ \\
\hline
\end{tabular}

a JH11 bacteria were always grown in the presence of naringenin. Lag is defined as the time between addition of Nod factor (NF) or bacteria and the peak of the first calcium spike. For the nonspiking Lysym22-1 mutant, a wild-type plant was processed in parallel in the same bath as a positive control. Only experiments in which the wild-type plant exhibited calcium spiking were counted in order to rule out false negatives caused by loss of activity of the Nod factor preparation. Lag and period are reported \pm the standard error of the mean. N.D. indicates not determined.

b All plants examined displayed calcium spiking.

${ }^{\mathrm{c}}$ Ehrhardt et al. 1996.

${ }^{\mathrm{d}}$ Wais et al. 2000.

e Walker et al. 2000. 
can trigger calcium spiking in the absence of bacteria. Analysis of timing and period indicate that by these parameters Nod factor-dependent calcium spiking in L. japonicus is indistinguishable from that seen in indeterminate nodulators such as alfalfa, M. truncatula, and pea. Thus, our experiments show that Nod factor-induced calcium spiking can be a component of both indeterminate and determinate nodule development and may be a conserved response of legumes to their rhizobial symbiont.

Finally, we used rhizobium-induced calcium spiking as a tool to dissect the Nod factor signaling pathway using $L$. japonicus nodulation mutants. We examined two mutants and found that one mutant, Ljsym30, exhibits a normal calcium spiking response, whereas the Ljsym22-1 mutant fails to respond to $M$. loti Nod factor with calcium spiking.

\section{Evolution of nodule development.}

Can analysis of rhizobium-induced calcium spiking contribute to the understanding of the evolution of nodule development? Legumes that form indeterminate nodules differ from those that form determinate nodules in their biochemistry and in their response to bacterial mutants as well as in patterns of nodule growth, infection, and morphogenesis. It is interesting that, despite their differences, determinate and indeterminate legume species share a calcium spiking response to their rhizobial partner. This observation suggests that calcium spiking may be a universal behavior of legumes to Nod factor and may have evolved early in the history of the legumes.

Although the process of nodule formation can differ from one type of legume to another, a common theme is the triggering of a plant developmental program by bacterially produced Nod factors. Perhaps the existence of a calcium spiking step in plants exhibiting such different developmental patterns reflects this common process of rhizobial recognition. Alternatively, a common calcium spiking step could reflect a common infection process. Although L. japonicus follows a different pattern of nodule development from the other calcium-spiking legumes, the initial mode of infection is the same in all of these species, infection through growing root hairs. It will be interesting to see whether a legume that is infected through epidermal cracks rather than through root hairs, such as peanut or Sesbania rostrata (Sprent 1989), also initiates epidermal calcium spiking in response to its rhizobial partner or whether calcium spiking is a prelude to root hair infection.

\section{The calcium spiking assay can be used to dissect the symbiosis pathway.}

Recently, several L. japonicus mutants that are blocked in the very early steps of nodulation have been described (Imaizumi-

Table 2. Symbiotic phenotypes and calcium response in Lotus japonicus mutants $^{\mathrm{a}}$

\begin{tabular}{lccc}
\hline & Ljsym22-1 & Ljsym30 & Wild type \\
\hline Calcium spiking & - & + & + \\
Root hair curling & $-{ }^{\mathrm{b}}$ & $?$ & + \\
Cortical cell division & - & \pm & + \\
Infection & - & $?$ & + \\
LjENOD2 expressed & - & - & + \\
LjENOD40 expressed & - & - & + \\
Leghemoglobin expressed & - & - & + \\
Mycorrhizal formation $^{\mathrm{c}}$ & - & - & + \\
\hline
\end{tabular}

a Symbiotic phenotype data from Szczyglowski et al. (1998). - indicates lack of response, + indicates presence of response, and ? indicates response unknown.

${ }^{\mathrm{b}} \mathrm{K}$. Szczyglowski, personal communication.

${ }^{\mathrm{c}}$ M. Parniske, F. de Bruijn, and K. Szczyglowski, personal communication.
Anraku et al. 1997; Schauser et al. 1998; Szczyglowski et al. 1998). The earliest response to $M$. loti assayed in these mutants was root hair deformation, which takes hours to develop. In contrast, calcium spiking is a response that occurs within minutes of encountering either the bacterial symbiont or Nod factor and can be used to identify mutants defective very early in the rhizobium-legume interaction. In particular, we expect that mutations in the receptor or in genes required for early signal transduction steps may block calcium spiking, whereas mutations in genes that function later in the pathway may allow Nod factor-induced calcium spiking.

We examined two L. japonicus mutants that are blocked at an early stage in the nodulation process and found that one mutant, Ljsym30, is able to respond to purified Nod factor with calcium spiking but that the Ljsym22-1 mutant is not. It is perhaps not surprising that Ljsym30 exhibits a normal calcium spiking response, since it is blocked somewhat later in development of the symbiosis than Ljsym22-1. Although Ljsym30 mutants fail to express many early nodulin genes, they do initiate cortical cell divisions, which probably occur more than a day after inoculation with $M$. loti (Table 2). Calcium spiking, on the other hand, starts within 20 min of addition of Nod factor or preinduced bacteria. The calcium spiking-defective Ljsym 22-1 mutant, however, is blocked much earlier in the rhizobium symbiosis; root hairs fail to deform, and cortical cells do not divide (Table 2).

\section{A common pathway for Nod factor perception?}

Our results indicate that the early Nod factor response pathway appears to be highly conserved in the papillionoid legumes. A key feature of this pathway is repetitive calcium spiking that begins minutes after exposure to bacterial Nod factor. Mutants defective in the calcium-spiking step fail to exhibit the earliest morphological changes associated with Nod factor, i.e., root hair deformation. Rather, the root hairs of these calciumspiking mutants swell at the tips in response to Nod factor but do not branch or curl (Wais et al. 2000; Walker et al. 2000).

The recent identification of a leucine-rich repeat receptor kinase required for nodulation in several legume species indicates a common step in the immediate Nod factor response pathway and demonstrates that Mtdmi2, alfalfa MN-1008, Pssym19, and Ljsym2 are homologs (Endre et al. 2002; Stracke et al. 2002). M. truncatula and pea each have a second gene that functions genetically at the same point as this receptor kinase, Mtdmil and Pssym8. Here, we show that Ljsym22, like Mtdmil and Psym8, is required for rhizobium-induced calcium spiking. Rhizobium-induced root hair changes have not yet been well characterized in the Ljsym22-1 mutant, although deformation has not been observed (K. Szczyglowski, personal communication). The Ljsym4-1 and Ljsym4-2 mutants, however, which are allelic to Ljsym22-1 (M. Parniske, personal communication) are blocked at tip-swelling, just as calcium spiking-defective nodulation mutants are in other legumes (Bonfante et al. 2000). Thus, Ljsym22/Ljsym4 act at the same point in the Nod factor signal transduction pathway as Mtdmil and Pssym8 and raises the possibility that these genes may be homologs. Because mutations in these genes block rhizobium-induced calcium spiking, Ljsym22/Ljsym4 and their counterparts in pea and M. truncatula are candidates for genes involved in transduction of the Nod factor signal upstream of calcium spiking or in the actual mechanism of calcium spiking itself.

\section{MATERIALS AND METHODS}

\section{Bacterial strains and general growth conditions.}

Bacterial strains used in this study are based on M. loti NZP2235 (Jarvis et al. 1982) and were all grown in tryptone 
yeast (TY) medium (Beringer 1974) at $30^{\circ} \mathrm{C}$. JH11 was grown in the presence of $50 \mu \mathrm{g}$ of spectinomycin per ml.

\section{Expression of heterologous nodD gene.}

To clone the $R$. leguminosarum bv. trifolii nodD gene, including the promoter, the plasmid pRtRF101 (Fisher et al. 1985) was digested with $S p h \mathrm{I}$ and incubated with T4 DNA polymerase to create blunt ends. It was subsequently digested with KpnI, and the 1.9-kb fragment was ligated into pMB393 (Barnett et al. 2000) that had been digested with EcoRV and KpnI. The resulting clone contains 361 bp downstream and 601 bp upstream, such that nodD is driven by the endogenous promoter. The insert is the same as that constructed by Lopez-Lara and associates (1995) in pMP283, but the vector is based on the Bordatella bronchiseptica broad-host-range plasmid pBBR1MCS (Kovach et al. 1994).

Plasmid pJH101 was transferred from E. coli into $M$. loti NZP2235 cells by triparental conjugation (Glazebrook and Walker 1991) using the helper plasmid pRK600 (Finan et al. 1986). The resulting strain is JH11.
Plant strains and growth conditions.

L. japonicus symbiotic mutants Ljsym22-1 and Ljsym30 (Szczyglowski et al. 1998) and the wild-type parental ecotype B-129-S9 Gifu (Handberg and Stougaard 1992) were the gift of K. Szczyglowski and F. de Bruijn, Michigan State University, East Lansing, U.S.A. For calcium spiking assays, L. japonicus seeds were scarified $20 \mathrm{~min}$ in concentrated sulfuric acid, were rinsed twice in sterile distilled water, were surface-sterilized for $10 \mathrm{~min}$ in $70 \%$ ethanol and 3\% hydrogen peroxide, and were rinsed six to eight times in sterile distilled water. Seeds were then imbibed for $4 \mathrm{~h}$ of shaking at room temperature and were germinated overnight in the dark at room temperature in a damp, inverted petri dish sealed with Parafilm. Seedlings were transferred to $10 \times 10 \mathrm{~cm}$ petri dishes, containing BNM agar (Ehrhardt 1992) and sealed with surgical tape (1535-1; 3M Health Care, St. Paul, MN, U.S.A.), and were placed at a near vertical position in a plant growth chamber. Plants were grown for 1 to 2 days at $24^{\circ} \mathrm{C}$ with a $16 \mathrm{~h}$ light and $8 \mathrm{~h}$ dark cycle and a light intensity of $60 \mu \mathrm{moles} / \mathrm{m}^{2} / \mathrm{s}$.

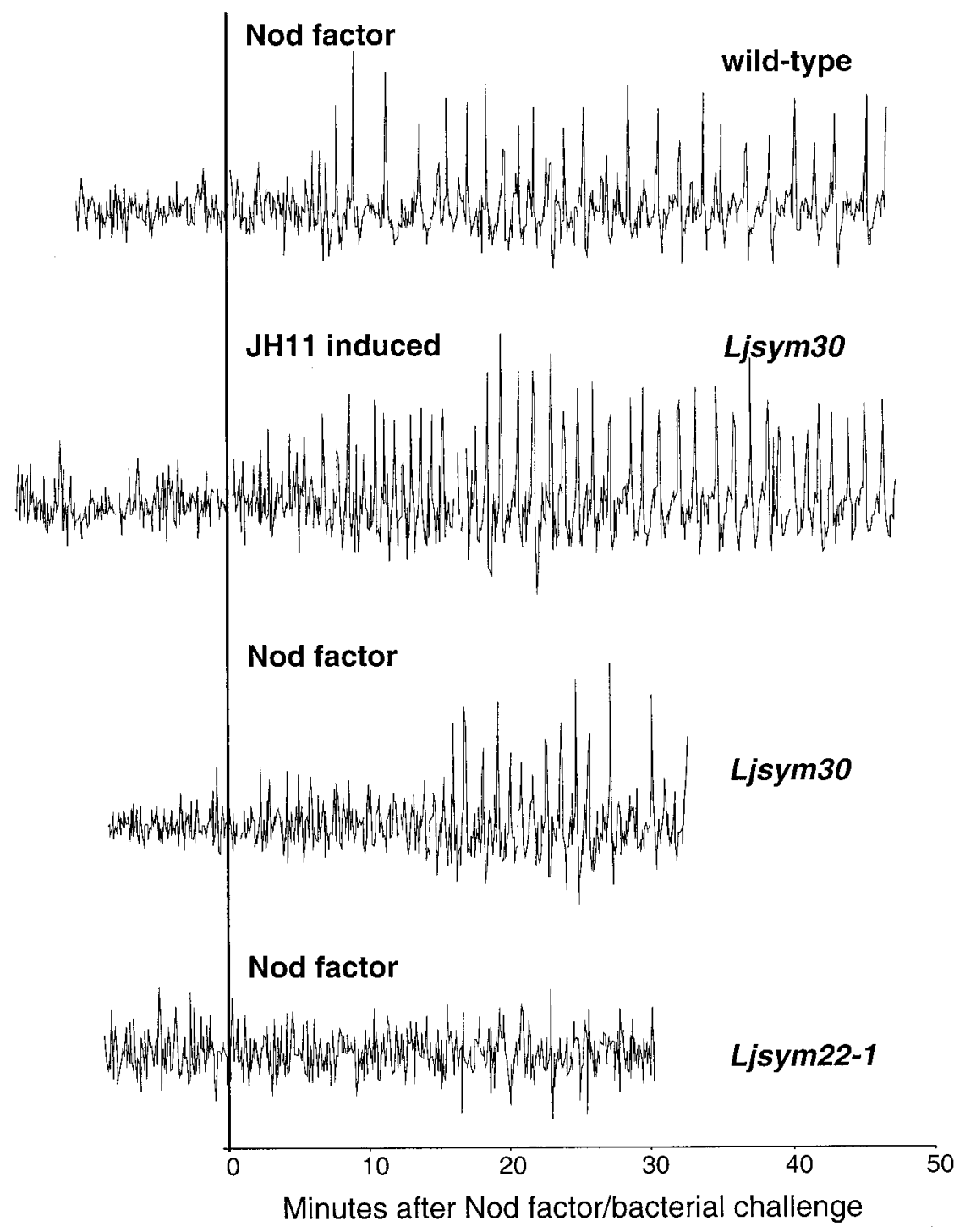

Fig. 2. Calcium spiking in wild-type and mutant root hairs. Each trace represents calcium levels in an individual root hair cell. Purified Nod factor or induced bacteria were added at time 0. Relative calcium levels were monitored using Oregon green fluorescence. Data was graphed as the difference in fluorescence intensity between sequential timepoints. For the nonspiking Lysym22-1 mutant, a wild-type plant processed in parallel in the same bath as a positive control exhibited wild-type calcium spikes (data not shown). 


\section{The calcium spiking assay.}

Plants. A chamber accessible from the top was constructed by sealing with silicon grease (Corning Inc., Corning, NY, U.S.A.) a plexiglass chamber frame onto a large glass coverslip (48 × 60 mm; PGC Scientific, Frederick, MD, U.S.A.). Intact seedlings ( 1 day old) were clamped (using silicon grease) between chamber and coverslip such that their roots were in an open, water-tight well that could be viewed from below (through the coverslip) and reached from above. The well was filled with $2 \mathrm{ml}$ BNM medium (Ehrhardt et al. 1992), and individual root hairs were injected with Oregon Green-dextran dye (D-7170; Molecular Probes, Eugene, OR, U.S.A.) by iontophoresis as described (Ehrhardt 1996). The 10,000 MW dextran prevents the dye from being sequestered away from the cytoplasm (Ehrhardt et al. 1996). Calcium imaging was carried out on a Nikon inverted TE200 microscope equipped with an FITC filter (41 High Q series, excitation $480 \pm 20 \mathrm{~nm}$, dichroic 505 long pass, emission $535 \pm 25 \mathrm{~nm}$; Chroma Technology, Brattleboro, VT, U.S.A.) and a neutral density filter (0.6 optical density) and a $20 \times$ CFI plan apochromat objective. Fluorescence imaging was performed using a Princeton Instruments (Trenton, NJ, U.S.A.) charge-coupled device (CCD)-1360SO cooled 1$\mathrm{MHz}$ CCD (Sony front-illuminated interline array) camera display. Images were collected every $5 \mathrm{~s}$ with a $200 \mathrm{~ms}$ exposure time and $2 \times 2$ binning, using METAFLUOR software from Universal Imaging (West Chester, PA, U.S.A.). Multiple cells on the same plant were imaged simultaneously. After approximately $20 \mathrm{~min}$ of imaging to collect a baseline for unstimulated cells, bacteria or purified Nod factor was added directly to the bath. Root hair cells were imaged for 30 to 40 min after addition of bacteria.

Bacteria. JH11 was grown overnight in TY medium containing $50 \mu \mathrm{g}$ of spectinomycin per $\mathrm{ml}$, then was diluted to an optical density at $600 \mathrm{~nm}\left(\mathrm{OD}_{600}\right)$ of 0.1 in fresh media (with antibiotic). At this point the nod gene inducer naringenin (LopezLara et al. 1995) was added to a final concentration of $1 \mu \mathrm{M}$, and the culture was grown for 20 to $24 \mathrm{~h}$ to an $\mathrm{OD}_{600}$ of approximately 1.0 to 1.6 . Bacteria were washed and resuspended in $\mathrm{BNM}$ and then added to the bath to give a final $\mathrm{OD}_{600}$ of 0.015 to 0.025 .

Nod factor. Purified Nod factor isolated from $M$. loti R7A (Sullivan et al. 1995) was the gift of C. Pacios Bras and H. Spaink. Both a high-pressure liquid chromatography (HPLC)purified and a crude fraction were tested, and each worked equally well at inducing calcium spiking. No significant difference in lag and period between spikes induced by different Nod factor preparations was observed. Purified Nod factor in dimethyl sulfoxide (DMSO) was diluted 1:250 in BNM to make a working stock and was used at a final bath dilution of 1:10,000. The crude Nod factor fraction was also stored in DMSO and was diluted 1:250 in BNM containing 1\% CHAPS (3-[(3-cholamidopropyl)-dimethyl ammonio]-1-propanesulfonate).

$M$. loti Nod factor is more hydrophobic than that produced by Sinorhizobium meliloti, and the addition of CHAPS to the stock dilution allowed it to be stored for longer periods of time without losing activity and made it possible to use much lower concentrations. Crude Nod factor was active at low dilutions and was routinely used at a dilution of 1:250,000.

Calculations. Data from the Metafluor log file for each experiment were imported into Microsoft Excel, in which all calculations were performed. Raw fluorescence data were corrected for background by subtracting the value of the fluorescence intensity of a region of the image away from the plant from the values for measured regions. Since Oregon Green is not a ratiometric dye, it cannot be used to measure the amplitude of calcium spikes. In addition, it is not possible to account for changes due to differences in cell thickness or local dye con- centration. As a result, in Oregon Green-dextran-injected root hairs, there is a baseline drift in fluorescence intensity. To easily distinguish the calcium spiking behavior from baseline fluctuations, we transformed the raw fluorescence data by subtracting the values for the fluorescence intensity $(\mathrm{FI})$ of adjacent timepoints using the function $\Delta \mathrm{FI}=\mathrm{FI}_{(\mathrm{n}+1)}-\mathrm{FI}_{\mathrm{n}}$, as described by Wais and associates (2000). Here, $\Delta$ FI represents the point to point change in fluorescence intensity, and FI represents the intensity measurements at timepoints $n+1$ and $n$. This function minimizes baseline drift and emphasizes rapid changes in fluorescence intensity characteristic of calcium spiking.

All subsequent calculations were carried out on the subtracted data. Calcium spikes are characterized by sudden changes in calcium levels, which are reflected as large change in fluorescence intensity $(\Lambda F I)$. Individual spike peaks were compared to the average change in fluorescence within a root hair. Only measurements of $\Lambda F I$ that exceeded twice the standard deviation of the average $\Lambda \mathrm{FI}$ for that cell were defined as calcium spikes. We used this definition of calcium spikes to calculate the lag before spiking initiated and the period of spiking. The lag from the addition of Nod factor or bacteria to the onset of spiking was calculated by measuring the time from addition of the stimulus to the first spike peak. The period between calcium spikes was calculated by measuring the time between spike peaks for at least 10 consecutive spikes at the beginning of the spiking period. We found that the period of calcium spiking increased over time in several root hairs, just as has been observed for pea (Walker et al. 2000). Therefore, we determined period using data only from the first 10 to $20 \mathrm{~min}$ after initiation of calcium spiking. Standard error of the mean was calculated by dividing the standard deviation by the square root of $n$, where $n$ is the number of imaged cells.

\section{ACKNOWLEDGMENTS}

This work was supported by the Howard Hughes Medical Institute and by Department of Energy (DOE) Energy Biosciences grant DE-FG0390ER20010 to S. R. L. and by U.S. Department of Agriculture experiment station grant no. VT-BO-00804 to J. M. H. We thank C. Pacios Bras and H. Spaink for the kind gift of $M$. loti Nod factor, K. Szcglowski and F. de Bruijn for the L. japonicus symbiotic mutants, B-129-S9 Gifu wildtype line, and the $M$. loti NZP2235 strain, D. Ehrhardt for helpful discussions, and M. Tierney and the anonymous reviewers for comments on the manuscript. We would also like to thank members of the laboratory: in particular, S. Shaw for constructing the Plexiglas injection chamber and setting up the microscope and injection system, R. Mitra for her calcium spiking analysis program, and V. Oke, B. Fisher, E. Engstrom, R. Mitra, and S. Shaw for helpful discussions and comments on the manuscript.

\section{LITERATURE CITED}

Allen, G. J., Chu, S. P., Harrington, C. L., Schumacher, K., Hoffmann, T., Tang, Y. Y., Grill, E., and Schroeder, J. I. 2001. A defined range of guard cell calcium oscillation parameters encodes stomatal movements. Nature 411:1053-1057.

Barnett, M. J., Oke, V., and Long, S. R. 2000. New genetic tools for use in the Rhizobiaceae and other bacteria. BioTechniques 29:240-245.

Bauer, C. S., Plieth, C., Hansen, U.-P., Sattelmacher, B., Simomnis, W., and Schönknecht, G. 1997. Repetitive $\mathrm{Ca}^{2+}$ spikes in a unicellular green alga. FEBS (Fed. Eur. Biochem. Soc.) Letters 405:390-393.

Beringer, J. E. 1974. R factor transfer in Rhizobium leguminosarum. J. Gen. Microbiol. 84:118-198.

Berridge, M. J., Bootman, M. D., and Lipp, P. 1998. Calcium-A life and death signal. Nature 395:645-648.

Bonfante, P., Genre, A., Faccio, A., Martini, I., Schoauser, L., Stougaard, J., Webb, J., and Parniske, M. 2000. The Lotus japonicus Ljsym4 gene is required for the successful symbiotic infection of root epidermal cells. Mol. Plant-Microbe Interact. 13:1109-1120.

Cárdenas, L., Feijó, J. A., Kunkel, J. G., Sánchez, F., Holdaway-Clarke, T., Hepler, P. K., and Quinto, C. 1999. Rhizobium Nod factors induce increases in intracellular free calcium and extracellular calcium influxes in bean root hairs. Plant J. 19:347-352. 
Cárdenas, L., Holdaway-Clarke, T., Sánchez, F., Quinto, C., Feijó, J. A., Kunkel, J. G., and Hepler, P. K. 2000. Ion changes in legume root hairs responding to nod factors. Plant Phys. 123:443-451.

Dolmetsch, R. E., Xu, K., and Lewis, R. S. 1998. Calcium oscillations increase the efficiency and specificity of gene expression. Nature 392:933-936.

Ehrhardt, D. W., Atkinson, E. M., and Long, S. R. 1992. Depolarization of alfalfa root hair membrane potential by Rhizobium meliloti Nod factors. Science 256:998-1000.

Ehrhardt, D. W., Wais, R., and Long, S. R. 1996. Calcium spiking in plant root hairs responding to Rhizobium nodulation signals. Cell 85:673-681

Endre, G., Kereszt, A., Kevei, Z., Mihacea, S., Kaló, P., and Kiss, G. B. 2002. A receptor kinase gene regulating symbiotic nodule development. Nature 417:962-966.

Felle, H. H., Kondorosi, E., Kondorosi, A., and Schultze, M. 1998. The role of ion fluxes in Nod factor signaling in Medicago sativa. Plant $\mathrm{J}$. 13:455-463.

Finan, T. M., Kunkel, B., De Vos, G. F., and Signer, E. R. 1986. Second symbiotic megaplasmid in Rhizobium meliloti carrying exopolysaccharide and thiamine synthesis genes. J. of Bacteriol. 167:66-72.

Fisher, R. F., Tu, J. K., and Long, S. R. 1985. Conserved nodulation genes in Rhizobium meliloti and Rhizobium trifolii. Appl. Environ. Microbiol. 49:1432-1435.

Gehring, C. A., Irving, H. R., Kabara, A. A., Parish, R. W., Boukli, N. M., and Broughton, W. J. 1997. Rapid, plateau-like increases in intracellular free calcium are associated with Nod factors-induced root-hair deformation. Mol. Plant-Microbe Interact. 7:791-802.

Glazebrook, J., and Walker, G. C. 1991. Genetic Techniques in Rhizobium meliloti. Methods Enzymol. 204:398-418.

Handberg, K., and Stougaard, J. 1992. Lotus japonicus, an autogamous, diploid legume species for classical and molecular genetics. Plant J. 2:487-496.

Hayashi, M., Imaizumi-Anraku, H., Akao, S., and Kawaguchi, M. 2000. Nodule organogenesis in Lotus japonicus. J. Plant Res. 113:489-495.

Heidstra, R., and Bisseling, T. 1996. Nod factor-induced host responses and mechanisms of Nod factor perception. New Phytologist 133:2543.

Hirsch, A. M. 1992. Tansley review No. 40. Developmental biology of legume nodulation. New Phytology 122:211-237.

Imaizumi-Anraku, H., Kawaguchi, M., Koiwa, J., Akao, S., and Syono, K. 1997. Two ineffective-nodulating mutants of Lotus japonicus-Different phenotypes caused by the blockage of endocytotic bacterial release and nodule maturation. Plant Cell Physiol. 38:871-881.

Jarvis, B. D. W., Pankhurst, C. E., and Patel, J. J. 1982. Rhizobium loti, a new species of legume root nodule bacteria. Int. J. Syst. Bacteriol. 32:378-380.

Kovach, M. E., Phillips, R. W., Elzer, P. H., Roop, R. M. I., and Peterson, K. M. 1994. pBBR1MCS: A broad-host-range cloning vector. Biotechniques 16:800-802

Li, W.-H., Llopis, J., Whitney, M., Zlokarnik, G., and Tsien, R. Y. 1998. Cell-permeant caged $\mathrm{InsP}_{3}$ ester shows that $\mathrm{Ca}^{2+}$ spike frequency can optimize gene expression. Nature 392:936-941.
Lopez-Lara, I. M., van den Berg, J. D. J., Thomas-Oates, J. E., Glushka, J., J., L. B. J., and Spaink, H. P. 1995. Structural identification of the lipo-chitin oligosaccharide nodulation signals of Rhizobium loti. Mol. Microbiol. 15:627-638.

McAinsh, M. R., Webb, A. A. R., Taylor, J. E., and Hetherington, A. M. 1995. Stimulus-induced oscillations in guard cell cytosolic free calcium. Plant Cell 7:1207-1219.

Meyer, T., and Stryer, L. 1988. Molecular model for receptor-stimulated calcium spiking. Proc. Natl. Acad. Sci. U.S.A. 85:5051-5055.

Niwa, S., Kawaguchi, M., Imaizumi-Anraku, H., Chechetka, S. A. Ishizaka, M., Ikuta, A., and Kouchi, H. 2001. Responses of a model legume Lotus japonicus to lipochitin oligosaccharide nodulation factors purified from Mesorhizobium loti JRL501. Mol. Plant-Microbe Interact. 14:848-856.

Schauser, L., Handberg, K., Sandal, N., Stiller, J., Thykjaer, T., Pajuelo, E., Nielsen, A., and Stougaard, J. 1998. Symbiotic mutants deficient in nodule establishment identified after T-DNA transformation of Lotus japonicus. Mol. Gen. Genet. 259:414-423.

Sprent, J. I. 1989. Which steps are essential for the formation of functional legume nodules? New Phytologist 111:129-153.

Staxén, I., Pical, C., Montgomery, L. T., Gray, J., Hetherington, A. M., and McAinsh, M. 1999. Abscisic acid induces oscillations in guardcell cytosolic free calcium that involve phosphinositide-specific phospholipase C. Proc. Natl. Acad. Sci. U.S.A. 96:1779-1784.

Stracke, S., Kistner, C., Yoshida, S., Mulder, L., Sato, S., Kaneko, T., Tabata, S., Sandal, N., Stougaard, J., Szczyglowski, K., and Parniske, M. 2002. A plant receptor-like kinase required for both bacterial and fungal symbiosis. Nature 417:959-962.

Sullivan, J. T., Patrick, H. N., Lowther, W. L., Scott, D. B., and Ronson, C. W. 1995. Nodulating strains of Rhizobium loti arise through chromosomal symbiotic gene transfer in the environment. Proc. Natl. Acad. Sci. U.S.A. 92:8985-8989

Szczyglowski, K., Shaw, R. S., Wopereis, J., Copeland, S., Hamburger D., Kasiborski, B., Dazzo, F. B., and deBruin, F. J. 1998. Nodule organogenesis and symbiotic mutants of the model legume Lotus japonicus. Mol. Plant-Microbe Interact. 11:684-697.

Thomas, A. P., Bird, G. S. J., Hajnoczky, G., Robb-Gaspers, L. D., and Putney, J. W., Jr. 1996. Spatial and temporal aspects of cellular calcium signaling. FASEB (Fed. Am. Soc. Exp. Biol.) J. 10:1505-1517.

Wais, R. J., Galera, C., Oldroyd, G., Catoira, R., Penmetsa, R. V., Cook, D., Gough, C., Dénarié, J., and Long, S. R. 2000. Genetic analysis of calcium spiking responses in nodulation mutants of Medicago truncatula. Proc. Natl. Acad. Sci. U.S.A. 97:13407-13412.

Wais, R. J., Keating, D. H., and Long, S. R. 2002. Structure-function analysis of Nod factor-induced root hair calcium spiking in rhizobiumlegume symbiosis. Plant Phys. 129:211-224.

Walker, S. A., Viprey, V., and Downie, J. A. 2000. Dissection of nodulation signaling using pea mutants defective for calcium spiking induced by Nod factors and chitin oligomers. Proc. Natl. Acad. Sci. U.S.A. 97:13413-13418.

Wais, R. J., Wells, D. H., and Long, S. R. 2002. Analysis of differences between Sinorhizobium meliloti 1021 and 2011 strains using the host calcium spiking response. Mol. Plant-Microbe Interact. 15:1245-1252. 